\section{All wired up}

The ocean floor is being covered with remote-controlled observatories, letting oceanographers keep tabs on the sea without getting wet. Jon Copley investigates.

$\mathrm{T}$ he ocean floor is an exciting place to visit, but you might not want to live there. Fortunately, those who want to keep an eye on what goes on beneath the waves now have an alternative. Instead of trying to colonize the sea floor, marine scientists are planning networks of unstaffed seafloor observatories across the globe. Connected by fibre-optic cables or linked to satellite buoys, this wet-world-web will let oceanographers make long-term measurements and run experiments in the depths without leaving their desks.

Back in the 1960s it seemed we were on the verge of living under the sea, gadding about in submersibles while pet porpoises fetched the morning papers. To show that people could live underwater, Jacques Cousteau famously developed the Conshelf habitats of basic undersea homes that could accommodate several people at depths of 10 to 100 metres, complete with a garage for a diving saucer. The US Navy SEALAB experiments, which actually used a porpoise to deliver mail from the surface, explored the limits of undersea living further. But the dream of colonizing the continental shelf proved costly and dangerous. Only one such project - the Aquarius habitat of the US National Oceanic and Atmospheric Administration (NOAA) - is still used as a research station, under 20 metres of water in the Florida Keys.

Nevertheless, a long-term window on the ocean depths has remained oceanographers' dream. The classic method of collecting oceanographic data by dropping instruments off the side of a ship comes with a persistent problem. It only provides a snapshot of the temperature, salinity and other properties of a single mass of water at a single point in time. Picking out trends from such pinpoints of data can be tricky. Some missions aim to sail the same track repeatedly, collecting the same kind of data each month. Experiments of this kind off the coasts of Hawaii and Bermuda have shown an intriguing fluctuation in the extent that these ocean regions act as a sink for atmospheric carbon dioxide $^{1,2}$. But divining the extent of, or the

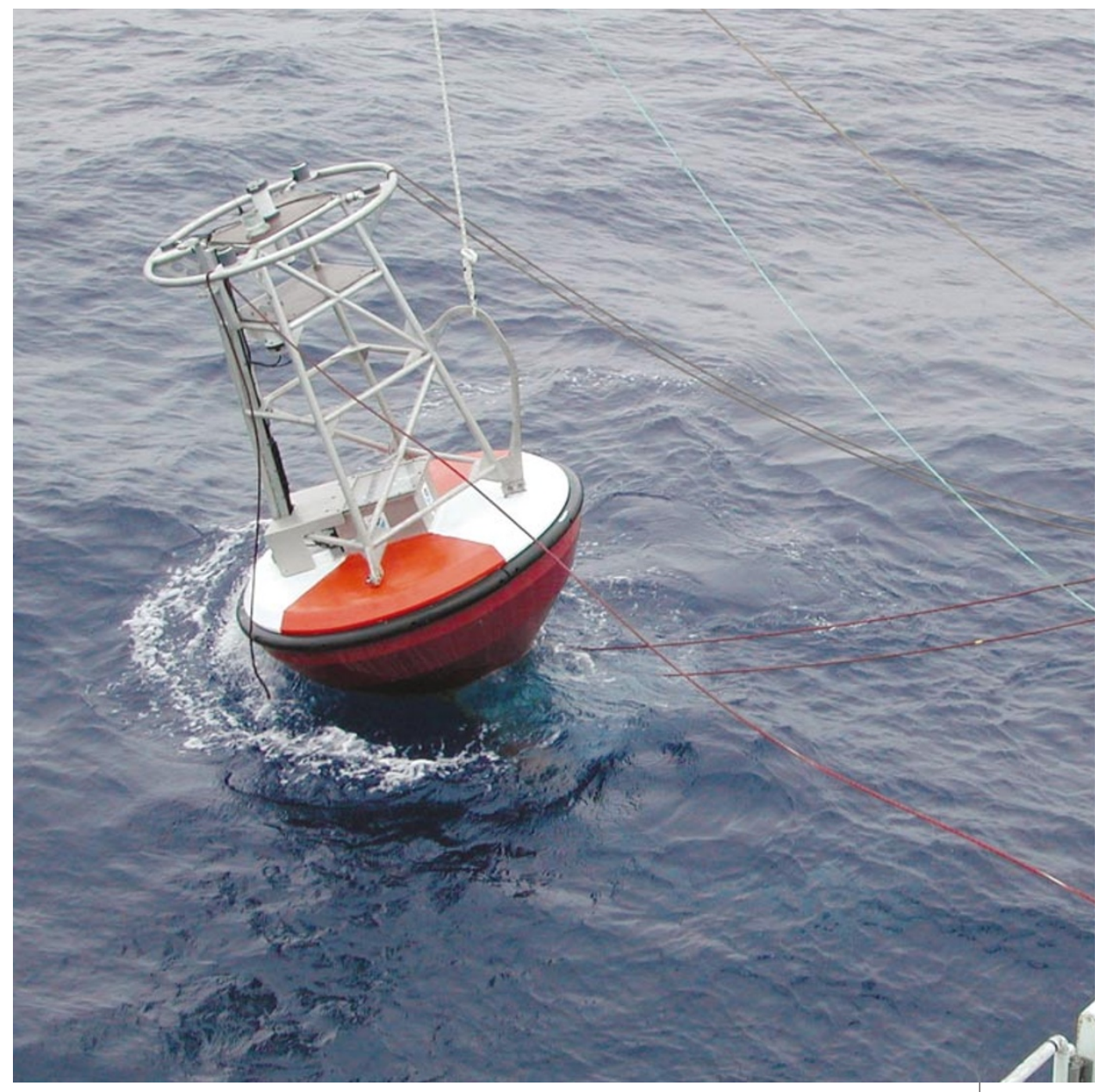

reason for, those fluctuations is difficult without more data. Satellites, on the other hand, can provide a vast amount of nearly continuous data over great swathes of ocean. But they cannot pick out most of what happens beneath the surface. Ideally, marine scientists need a network of stations that give good coverage in both space and time.

\section{Take the plunge}

Underwater observatories can do just that. Early in January researchers will converge on San Juan in Puerto Rico to thrash out the priorities for future US efforts in this field. As part of a new Ocean Observatories Initiative, the National Science Foundation (NSF) has earmarked US\$200 million for infrastructure investment for both coastal and deep-ocean observatories. Meanwhile, researchers in Europe and Japan are also exploring ambitious plans for constellations of seafloor observatories. Over the next few decades it seems likely that a web of observatories will be spun out into the abyss.

The idea of a network of observation posts for long-term monitoring of the oceans was first realized during the cold war with the US Navy's SOSUS array, a collection of hydrophones draped across the Atlantic and Pacific to listen for Soviet submarines. Its sensitive ears could pick up low-frequency sounds at less than 1 watt at a range of several hundred kilometres - in the right conditions it could hear the songs of blue whales 3,000 kilometres away. When SOSUS was made available to civilian researchers in the 1990 s, it revealed previously unknown seismic rumblings that take place on mid-ocean ridges ${ }^{3}$ and provided insights into the migration of whales ${ }^{4}$. These results confirmed the scientific value of keeping a constant watch on the oceans.

Scientists now have far more ambitious plans in mind. The boldest is the North-East Pacific Time-series Undersea Networked Experiments (NEPTUNE), the brainchild of John Delaney at the University of Washington in Seattle and Alan Chave at Woods Hole Oceanographic Institution on Cape Cod, Massachusetts. NEPTUNE aims to wire up the entire Juan de Fuca plate - the slab of oceanic crust between the WashingtonOregon coast and the Juan de Fuca Ridge 500 $\mathrm{km}$ offshore - with a 3,000-km network of fibre-optic cable. Observatories plugged into 'nodes' on this network will provide a multidisciplinary playground for ocean scientists, as well as an early-warning earthquake system for the Pacific Northwest.

NEPTUNE is expected to cost a total of \$250 million, but Delaney is adamant about 


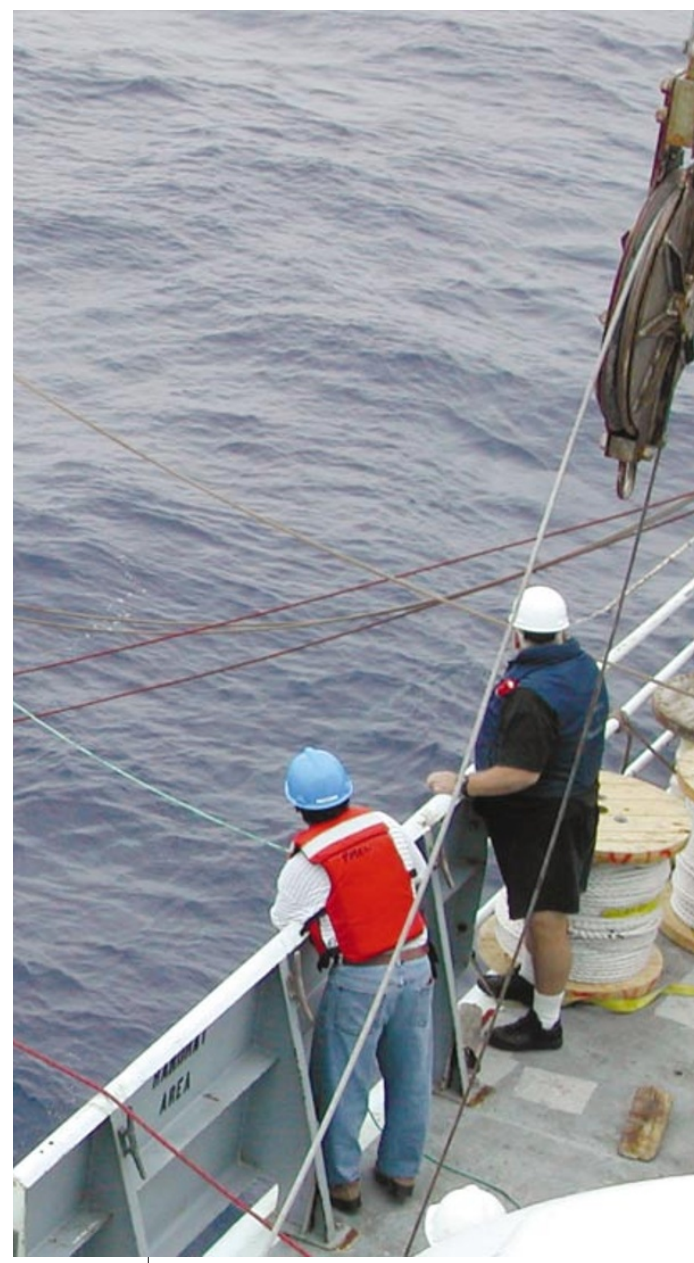

the benefits of such a system. "It will fundamentally transform the way that we study the ocean and the Earth, by providing real-time access and data flow to complex processes that are episodic," he says. These episodic events include eruptions on the mid-ocean ridge that seem to release huge plumes of hot water loaded with minerals ${ }^{5}$, which might feed the microbes that live in the water above the vents.

Plans for NEPTUNE have been in the pipeline for over a decade, but it is just now starting to pick up the cash it needs to become a reality. In October 2003, Canada announced Can\$62.4 million (US\$47.5 million) of funding for the project. And hopes are high that a good chunk of the NSF money for ocean observatories might end up in NEPTUNE's pocket.

Meanwhile, both the United States and Canada have funded two small-scale cabled observatories that should serve as test-beds for the project. One is VENUS, the Victoria Experimental Network Under the Sea, which will cover the Straits of Georgia and Juan de Fuca off British Columbia with the first sections of NEPTUNE's cable, scheduled to be laid next year. Keeping to the planetary theme, the other is MARS, the Monterey Accelerated Research System, which plans

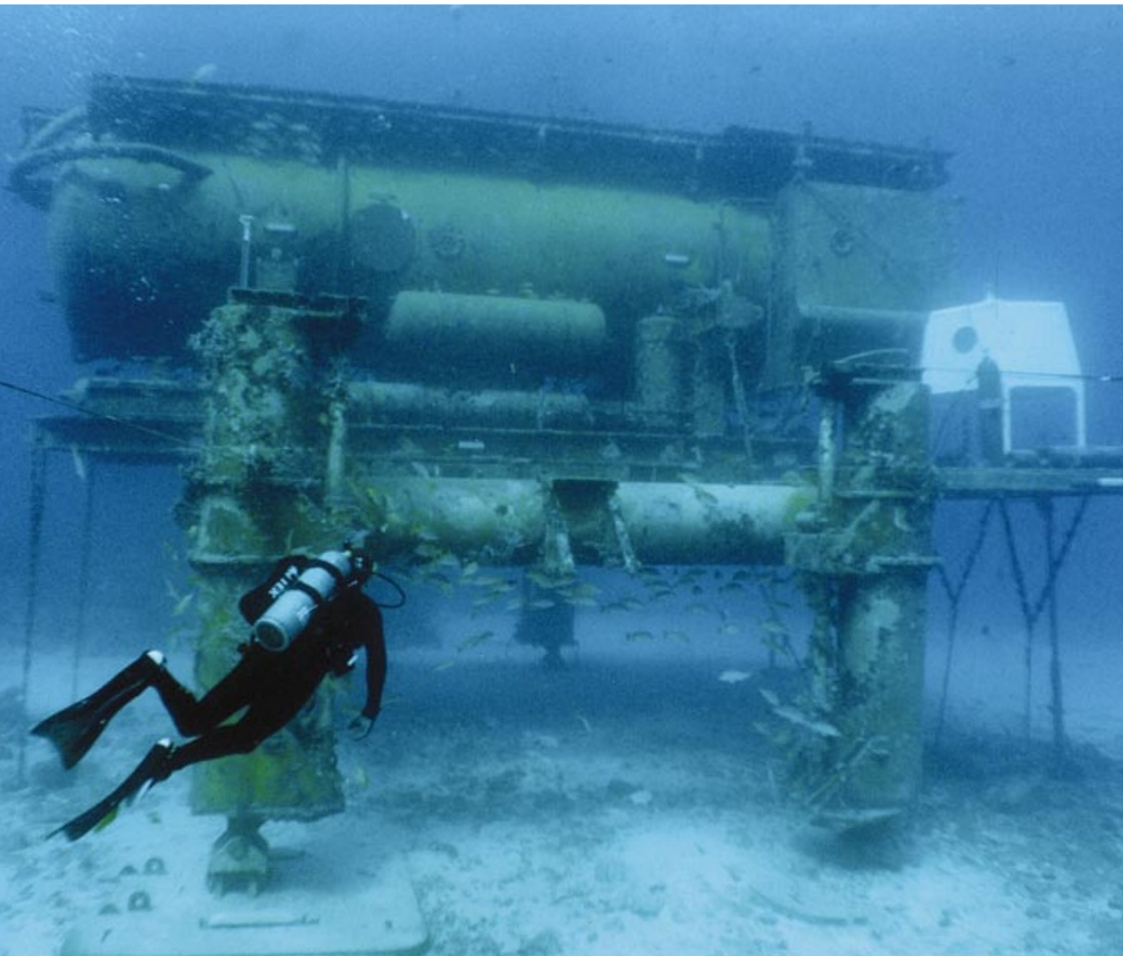

Science without scuba? Left, researchers deploy a buoy as part of NeMO Net, which will gather data from underwater sensors, providing a convenient alternative to seafloor stations such as Aquarius (above).

to deploy observatories in Monterey Bay, California. Both will allow scientists to keep a better watch on their coastal backyards, while providing an arena to develop NEPTUNE technology.

\section{Stay connected}

Delaney does not underestimate the technical challenges faced by regional networks such as NEPTUNE. The foremost is longterm maintenance. NEPTUNE is intended to run for at least two or three decades, with $3,000 \mathrm{~km}$ of fibre-optic cable linking 20 or 30 stations, each of which may have secondary extension cords reaching out over tens of kilometres to instrument packages. Keeping this network intact over remote and rugged seafloor terrain is not a trivial operation. In October 1997, the University of Hawaii deployed a seismic observatory on an undersea volcano using $45 \mathrm{~km}$ of fibre-optic cable donated by AT\&T. Although the observatory piped a wealth of data back to the shore, the cable short-circuited just six months after installation, and has not been brought back online since. A similar fate could lie in store for NEPTUNE cables crossing volcanically active regions of the Juan de Fuca Ridge.

Not all cable-tied projects fail. The Hawaii 2 Observatory (H2O), halfway between Hawaii and California, was built in 1998 using old coaxial AT\&T cables and hosts seismometers at a depth of 5,000 metres. Run by the Woods Hole Oceanographic Institution in Massachusetts, it is considered one of the triumphs of deep-sea wired observation, given the fact that it churns out real-time data from such a remote location. But if researchers do want to get around the cost and potential problems of cables, there is an alternative beaming data up to surface buoys.

The New Millennium Observatory, or NeMO Net, operated by NOAA, does just that. This 'net' consists of two sensors splayed on Axial Volcano, one of the active underwater volcanoes on the Juan de Fuca Ridge. These sensors beam information about temperature, chemistry and movement of the volcano's flanks by an acoustic signal up to a surface buoy, which provides a satellite link for researchers to receive real-time data and send commands to their instruments. Although satellite communications do not offer the same bandwidth as a fibre-optic connection, and can't feed power to instruments, they can be used in more remote areas without the expense of laying cable.

Meanwhile, on the other side of the world, the European Sea Floor Observatory Network (ESONET) consortium is exploring the possibility of rigging up the Atlantic and Mediterranean coasts. So far ESONET has received $\mathrm{E} 800,000$ (US\$983,200) for a feasibility study, which will report in May 2004. Unlike NEPTUNE, ESONET has no tectonic plate to serve as a focus for the project. Instead, the observatories will undertake a range of scientific projects such as assessing the impact of changes in sea ice in the Norwegian Sea on deep-water circulation and monitoring biodiversity in the North Atlantic and seismic activity in the Mediterranean. Ideally, 
the project will cover all European waters from the Arctic Ocean to the Black Sea, taking in an area comparable to continental Europe and a host of largely unexplored phenomena from cold-water corals to mud volcanoes.

European researchers already have considerable experience with deep-sea observatories. For example, in August 2001, Monty Priede's team at the University of Aberdeen, UK, deployed an autonomous lander a mobile observatory that carries its own battery pack and data-storage facilities - at a depth of 4,000 metres for 18 months, to the southwest of Ireland ${ }^{6}$. And European researchers coordinated by the Italian National Institute of Geophysics and Volcanology have used a satellite-buoy observatory to collect oceanographic and geological data from the depths near Sicily for the past seven months.

\section{World of experience}

ESONET brings together researchers from 14 institutions across the continent with such expertise. Rather than setting their sights on obtaining funding for a full network at the outset, they envisage a gradual growth of capability. "What we perceive is a smooth transition from using autonomous observatories to connecting them up to cables, as opportunities arise," says Priede, who is ESONET's coordinator. "I don't see the the European Commissio suddenly coming up with E100 million (US\$123 million) to install ESONET - that's not the way we're going."

Unlike NEPTUNE, ESONET would not be a single integrated network, but a federation of local networks covering different geographic regions. "We're not pretending that there will be a cable connected all the way from Norway to Sicily," says Priede. "But on a 20year timescale, I think we'll have a very significant monitoring capability around Europe."

To make this happen, ESONET members are exploring the possibility of sharing infrastructure with other partners, including astronomers. Researchers now working on a project to build a neutrino telescope 2,400 metres below the surface of the Mediterranean $\mathrm{Sea}^{7}$, for example, have already set up a cable connection to the shore to beam back their data. And that could be shared with seafloor observatories in the area.

The third big player in ocean observatories is Japan, which has traditionally been interested in picking up signals from seismic instruments on the sea floor to give an early warning of earthquakes and tsunamis, the giant waves they produce. Eight cabled observatories are already in place around the islands, mostly for earthquake observation. And researchers are planning the more ambitious ARENA (Advanced Real-time Earth Monitoring Network in the Area). Headed by Yuichi Shirasaki at the University of Tokyo, the ARENA project aims to provide a network of cabled observatories spanning the plate boundary along
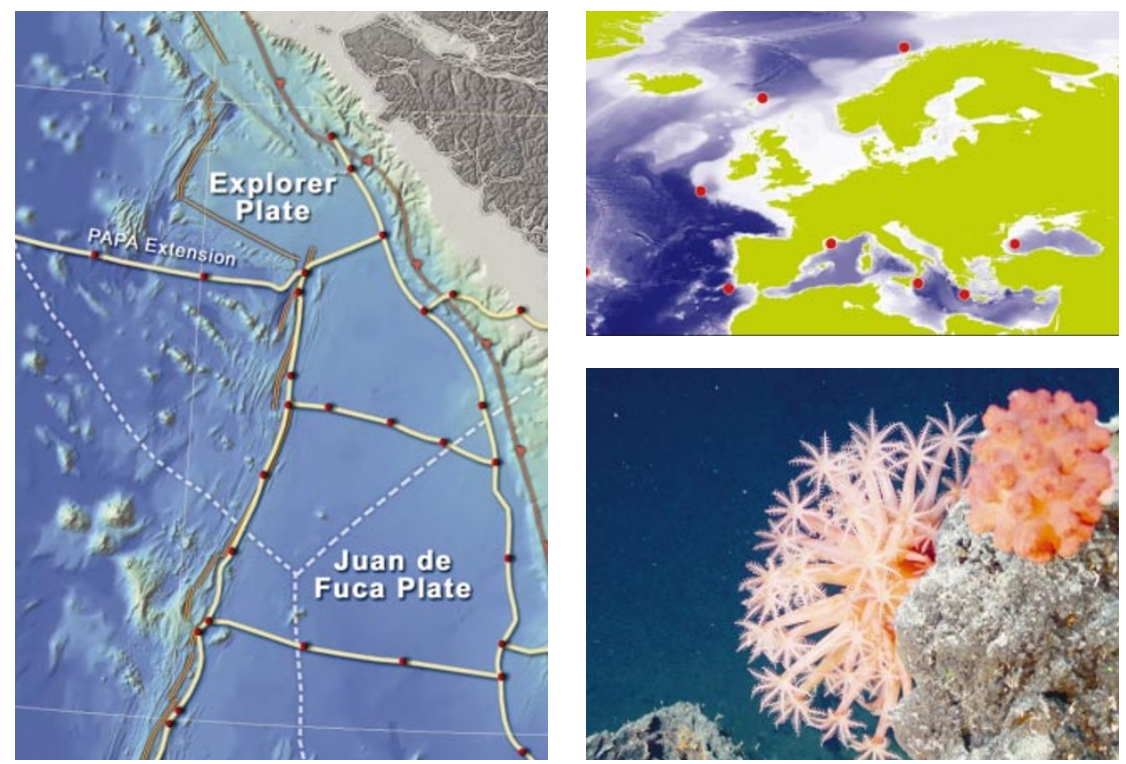

Underwater empires: the NEPTUNE and ESONET projects will position sensors around the US (left) and European (top right) coasts, respectively, studying everything from earthquakes to coral (above).

the Japan Trench. As with NEPTUNE and ESONET, researchers anticipate that the observatories will be multidisciplinary, allowing researchers to collect a suite of seismic, oceanographic and biological information.

While NEPTUNE, ESONET and ARENA are intended to probe the deeps, researchers in shallower waters have been enjoying the benefits of seafloor observatories for some time. Rutgers University, for example, runs LEO-15, a long-term ecosystem observatory lying $16 \mathrm{~km}$ off the New Jersey coast. Its two nodes, which were designed by the Ocean Systems Laboratory at Woods Hole, Massachusetts, host sensors that monitor temperature and currents, and take video images to stream back to the lab.

\section{Fishing for clues}

LEO-15 has proved eminently useful not only to scientists but also to fishermen along the East Coast. In 1976, the shellfish industry was devastated by a mysterious shortage of oxygen in the water. Pollution was the first suspect, but the culprit turned out to be a strong upwelling which brought an influx of nutrient-rich cold water towards the coast from deeper off-shore. This caused blooms of phytoplankton that later died and decayed, consuming much of the oxygen in the water. LEO-15 now gives fair warning of incoming upwelling waters, allowing the fishermen to plan for difficult times ahead.

One node of LEO-15 acts as a service station for the autonomous underwater vehicles that prowl around the observatory. Woods Hole's remote environmental sensing unit (REMUS) can dock with the node to download its data and recharge its batteries. Delaney expects a similar squadron of vehicles to scurry about the Juan de Fuca Plate like bees, visiting the nodes of the NEPTUNE network and col- lecting data from the gaps between them. The robotic craft could also be used to respond to episodic events detected by the network, for example moving in to sample and survey the epicentres of seismic activity.

Rutgers University also plans to hook LEO-15 up with similar projects, such as the Martha's Vineyard Coastal Observatory, to create a monitoring network covering most of the eastern seaboard. The project, nicknamed Cable Tie, plans to use retired transatlantic telephone cable to link the observatories. By combining underwater observatory data with satellite images, observations from radars that monitor oceansurface currents, measurements from oceanographic buoys and from vehicle missions, the network hopes to work out the carbon cycle of the continental shelf.

While the dream of life beneath the waves remains elusive, marine scientists are spending more and more time immersed in their medium through such 'telepresence'. Those with plans to extend this capability further are adamant about its benefits. "We've come a long way with the standard approaches of ships and satellites, but we've reached a stage where we cannot go much farther without this additional capability," Delaney argues. “That's not to say that this will replace ships or satellites by any means, but it's the next tool that we desperately need in order to move on."

Jon Copley is a freelance writer based in Southampton, UK.

1. Gruber, N., Keeling, C. D. \& Bates, N. R. Science 298,

2374-2378 (2002)

2. Dore, J. E., Lukas, R., Sadler, D. W. \& Karl, D. M. Nature 424, 754-757 (2003)

3. Fox, C. G. et al. Geophys. Res. Lett. 22, 131-134 (1995).

4. Charif, R. A., Clapham, P. J. \& Clark, C. W. Marine Mammal Science 17, 751-768 (2001).

5. Cowen, J. P. \& Baker, E. T. Deep-Sea Res. II 45, 2503-2511 (1998).

6. Bailey, D. M., Jamieson, A. J., Bagley, P. M., Collins, M. A. \&

Priede, I. G. Deep-Sea Res. I 49, 1519-1529 (2002).

7. Ball, P. Nature 419, 12-14 (2002). 